\title{
BMJ Open Unintentional fall-related mortality in the elderly: comparing patterns in two countries with different demographic structure
}

\author{
Marek Majdan, ${ }^{1,2}$ Walter Mauritz ${ }^{2}$
}

To cite: Majdan M, Mauritz W. Unintentional fallrelated mortality in the elderly: comparing patterns in two countries with different demographic structure. BMJ Open 2015;5: e008672. doi:10.1136/ bmjopen-2015-008672

- Prepublication history and additional material is available. To view please visit the journal (http://dx.doi.org/ 10.1136/bmjopen-2015008672).

Received 4 May 2015 Revised 16 July 2015 Accepted 24 July 2015

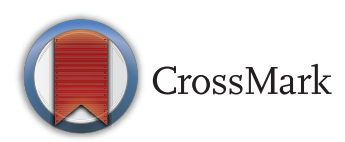

${ }^{1}$ Faculty of Health Sciences and Social Work, Department of Public Health, Trnava University, Trnava, Slovakia ${ }^{2}$ International Neurotrauma Research organization (INRO), Vienna, Austria

Correspondence to Dr Marek Majdan; mmajdan@truni.sk, mmajdan@igeh.org

\section{ABSTRACT}

Objectives: Falls are among the major external causes of unintentional injury and injury-related mortality in the elderly. The aim of this study was to compare the patterns of unintentional fall-related mortalities in two countries with different demographic structure: Slovakia and Austria in 2003-2010.

Methods: A study was conducted using death certificate data, trends of fall-related mortality in the elderly (over 65 years) in Austria and Slovakia were compared. Crude and age-standardised mortality rates were calculated. Rate ratios were used to quantify differences based on age, sex and country. The role of demographic structure and population ageing was considered.

Results: The annual average crude mortality for Slovakia was 28.82, for Austria 54.19 per 100000 person-years. Increasing rates were observed towards higher age in both countries. Males had higher mortality than females (1.18 times higher in Austria, 2.4 higher in Slovakia). In ages over 75 years rates were significantly higher in Austria, compared to Slovakia. Injuries to head (in males) and hip (in females) were most commonly the underlying cause of death. The proportion of populations over 65 and over 80 and rate of their increase were higher in Austria than in Slovakia.

Conclusions: We conclude that higher proportions of the elderly population of Austria could have contributed to the higher fall-related mortality rates compared to Slovakia, especially in females over 80 years. Our study quantified the differences between two countries with different structure of the elderly population and these findings could be used in planning future needs of health and social services and to plan prevention in countries where a rapid increase in age of the population can be foreseen.

\section{INTRODUCTION}

Falls are among the major external causes of unintentional injury and are commonly defined as inadvertently coming to rest on the ground, floor or other lower level, excluding intentional change in position to rest in furniture, wall or other objects. ${ }^{1}$ In

\section{Strengths and limitations of this study}

- The study is population based and includes all cases of fall-related death occurring in both countries.

- The unified methodology of data analysis and presentation strengthens the findings and their generalisability.

- The use of standard format administrative data and standard epidemiological presentation of the results (including standardisation) ensures the reproducibility of the study on other populations.

- Although the International Classification of Diseases (ICD-10) system was used in both countries, bias might have been introduced by individual variation in coding within or between the countries.

- The presented results suggest that the differences could be related to demographic structure but no causal evidence is presented.

the European Union (EU), every year 123000 people aged 60 and above die from the consequences of injuries, which represents $53 \%$ of all injury deaths. ${ }^{2}$ Falls are the major cause of injury-related fatalities in the elderly population of Europe (accounting for $28 \%$ of all cases), and as a consequence of increasing life expectancy they became a major public health and social care issue..$^{2-4}$ In 2010, falls in the elderly accounted for over $85 \%$ of years lived with disability in the population of 70 and older. ${ }^{5}$ About a third of people with age over 65 years fall each year and at the age of 80 years or more this proportion increases to $50 \% .^{2}{ }^{6}$ Accidents (environment related), gait/balance disorders and dizziness are the three major causes of falls in the elderly ${ }^{7}$ and medication such as oral anticoagulation may additionally increase the risk for mortality. ${ }^{8}$

Large between-country differences have been identified within Europe in overall, ${ }^{9}$ as well as injury-related mortality ${ }^{10}$ among the 
elderly. The proportion of injury-related deaths to all deaths in the elderly in Europe varies, too and ranges from 1 to $6 \%$. $^{2}$ Population ageing has a great impact on the number of falls occurring as falls exponentially increase with age-related biological change; population increase in the group of 80 years and older will therefore trigger substantial increase in fall-related injuries and fatalities. ${ }^{1}$ Socioeconomic inequalities in mortality were found to be present and persisting in a study analysing 11 European populations, which concluded that even if the relative inequalities would not increase in the future, the excess deaths that would occur would still be increasing due to the aging of the population. ${ }^{9}$ These findings imply that social and economic factors are strongly related to the changes in fall-related mortality rates.

In this study we hypothesised that the patterns of fallrelated mortalities among the elderly could differ based on the structure of the elderly population. Our aim was to compare the patterns of unintentional fall-related mortalities in two countries with different demographic structure: Slovakia and Austria in 2003-2010.

\section{METHODS}

An epidemiological study was conducted in order to compare the trends of unintentional fall-related mortality rates in the elderly population (65 years or older) of Slovakia and Austria and to observe differences based on age and sex. Additionally, the patterns of body regions with the most significant injury (listed as the underlying cause of death) were analysed and compared. The study focused on the entire population of both countries and the period under study was 2003-2010.

\section{Data sources and case definitions}

Administrative data that was obtained from the respective authorities in Slovakia and Austria was used for the investigation. In case of Slovakia a data set of all deaths occurring in the analysed period of years was obtained from the Statistical Office of the Slovak Republic. For Austria the same data was obtained from the Austrian Statistical Office. In both databases the external cause of death and the underlying cause of death was encoded using the International Classification of Diseases and Related Health problems, 10th edition (ICD-10). ${ }^{11}$ Age and sex of the deceased, year of death, underlying cause of death and external cause of injury were available in both data sets.

From the original data set, all fatalities that were caused by an unintentional fall were filtered in the first step (ICD-10 codes of W00-W19). Second, only persons with age of 65 years or more at the time of death were selected. Thus the final data sets that were used for the analysis in this study consisted of all cases of death occurring in the respective countries where the cause of injury was an unintentional fall and the victim was 65 years or older.
Population counts (annual averages) that were used to calculate mortality rates were also obtained from the statistical offices of Slovakia and Austria, separate for each year for ages 65 and older and for both sexes (they were grouped according to the age groups that were defined for the study).

\section{Variable definitions}

Age-group-specific and sex-specific mortality rates were calculated as a ratio of the number of cases and the population count in each category, recalculated to 100000 person-years. Crude overall mortality rates were calculated as ratios of the total number of deaths and average population count for each year, recalculated to 100000 person-years. Annual average mortality rates were calculated as ratios of the average annual number of deaths for 2003-2010 in the respective age/sex group and the average annual population count for 2003-2010 for that group, recalculated to 100000 person-years.

To produce internationally comparable results, age standardised mortality rates with $95 \%$ CIs were calculated for both countries for the analysed period. The direct method of standardisation was used and the WHO world population was used as the standard population. $^{12}$

\section{Description of the compared countries}

Both countries are located in central Europe. According to the World Bank, Austria had 8.747 million inhabitants in 2013 and the country's total Gross Domestic Product (GDP) in 2013 was $\$ 428.3$ billion. ${ }^{13}$ Slovakia had a total of 5.414 million inhabitants in 2013 and its GDP was $\$ 97.71$ billion. ${ }^{14}$ The Gross National Income per capita based on purchasing power parity was $\$ 45450$ in Austria and \$26 110 in Slovakia. ${ }^{15}$ According to Eurostat, the GDP per capita in Purchasing Power Standards was 126 in Austria and 65 in Slovakia (values over 100 are above the EU average). ${ }^{16}$ Based on the presented economy indicators it is clear that the economy level in Austria is higher compared to Slovakia. The life expectancy at birth in Austria was 81 years and in Slovakia 76 years for the period of 2005-2009 ${ }^{13}{ }^{14}$ ).

\section{Analysis outline and statistical methods}

Four age groups were created: 65-74, 75-84, 85-94 and 95 years and older. Crude mortality rates were calculated for both countries for each year and compared across the age groups and by sex. To provide a better measure of mortality rate differences between the compared groups, rate ratios with $95 \% \mathrm{CI}$ were calculated. In case of rate ratios between age groups, the group of 6574 years was taken as a reference and all other categories were compared to the rate in this age group. In case of rate ratios between sexes females were taken as a reference and the ratios in the male group are relative to the rates for females in the respective year. In addition, between-country rate ratios were calculated to better describe the differences in observed mortality rates in 
Slovakia and Austria. In this case, the rate ratios are presented as rates observed in Austria relative to rates observed in Slovakia.

As this is a population study, no inferential statistical analyses were performed. To analyse time trends the Mann-Kendall test for monotonic time series was applied and values of Kendall's $\tau$ were calculated. For all analyses, the $\mathrm{R}$ statistical programme was used. ${ }^{17}$

All rates presented in this paper were recalculated for 100000 person-years; for the paper to be easier to read we have omitted the denominator and the values of the rates are presented only. With the term 'elderly population' throughout the paper we refer to the population of 65 years or older. Owing to space limitations and better readability of the paper we only included the key tables and figures in the main text. However, more detailed data and results are made available online in an electronic supplementary material (ESM). We refer to tables and in the ESM as supplementary tables and figures. We encourage the readers to download and read this material as it contains important aspects of the analysed topic.

\section{Ethical considerations}

The study used solely administrative data that is in public domain. All data was obtained from the official institutions in both countries and was provided in a form that was in accordance with any data and privacy protection legislation. No ethical committee approval was therefore requested.

\section{RESULTS}

Based on the criteria defined for this study we have identified 5979 cases of unintentional fall-related fatalities in the elderly population of Austria and 1486 cases in Slovakia for the period under study. Of all cases in Austria, 56\% were female; in Slovakia the proportion of females was $41 \%$.

Table 1 presents the annual average mortality rates by age group and sex for both countries along with crude and age standardised overall mortality rates. Detailed calculations of annual mortality rates by age-groups and sex can be found in online supplementary tables S1 and $\mathrm{S} 2$ in the ESM. The annual average crude mortality rate for Slovakia was 28.82 and for Austria 54.19. When comparing mortality rates in the analysed age groups a clear increasing tendency was observed towards higher age in both countries and both sexes, with the highest rates in the age group of 95 years and older. The analysis of time trends (from 2003 to 2010) revealed an increasing trend of female and overall mortality rates in Slovakia (Kendall's $\tau 0.29$ for both) and a stagnation of rates in males $(\tau=0.07)$. On the other hand, female, male and overall mortality rates in Austria were decreasing over the analysed period $(\tau=-0.57 ;-0.57$ and -0.43$)$. Such trends were observed also for the age standardised rates (see figure 1 for details).

This tendency is documented by annual average rate ratios presented in table 2. Detailed calculations of annual mortality rate ratios by age-groups can be found in online supplementary tables S3 and S4 in the ESM. Overall, in Slovakia the rates suggest a 1.7 -fold increase in mortality rates in the group of $75-84$ years old, a 4.1-fold increase in the 85-94 group and an 8.2-fold increase in the 95 and older category, compared to $65-$ 74 years old as a reference. This phenomenon is more apparent in the female subpopulation (rate ratios of 2.8, 8.9 and 17.5 , respectively), than in the male population (rate ratios of 1.4, 2.8 and 6.4). In Austria, the rate ratios were 3.7, 12 and 28.4 overall; 5.6, 19.7 and 47 in females; and 3.1, 9.9 and 25.7, respectively in males. It is therefore clear that the increase of mortality rates by age is much more apparent in Austria than in Slovakia.

The rate ratios by sex presented in table 3 show that in both countries males were more likely to die of a fallrelated injury than females. On average for the period under study the mortality rates of males were 1.18 times higher in Austria and 2.4 times higher in Slovakia. These findings suggest that the difference in mortalities between sexes was less apparent in Austria.

Table 4 presents the rate ratios for each age group, year and sex in a between-country manner. Overall, the mortality rates in the age group of $65-74$ were lower in

\begin{tabular}{|c|c|c|c|c|c|c|c|c|}
\hline \multirow[b]{2}{*}{ Country } & \multirow[b]{2}{*}{ Subgroup } & \multirow[b]{2}{*}{$65-74$} & \multirow[b]{2}{*}{ 75-84 } & \multirow[b]{2}{*}{ 85-94 } & \multirow[b]{2}{*}{$95+$} & \multirow{2}{*}{$\begin{array}{l}\text { Total } \\
\text { Crude rate }\end{array}$} & \multicolumn{2}{|c|}{ Total Standardised $\dagger$} \\
\hline & & & & & & & Rate & $95 \% \mathrm{Cl}$ \\
\hline \multirow{3}{*}{ Slovakia } & Male & 37 & 52 & 101 & 207 & 45.48 & 46.57 & 46.54 to 46.6 \\
\hline & Female & 8 & 22 & 68 & 120 & 18.19 & 16.65 & 16.64 to 16.67 \\
\hline & Total & 19 & 33 & 77 & 139 & 28.82 & 28.22 & 28.21 to 28.23 \\
\hline \multirow[t]{3}{*}{ Austria } & Male & 25 & 79 & 249 & 633 & 59.69 & 60.63 & 60.61 to 60.65 \\
\hline & Female & 9 & 51 & 179 & 421 & 50.48 & 35.69 & 35.68 to 35.71 \\
\hline & Total & 16 & 61 & 197 & 461 & 54.19 & 45.03 & 45.02 to 45.04 \\
\hline
\end{tabular}

*Please see electronic supplementary material for detailed data calculated for each year under study. †Rates standardised for age by the direct method using the WHO World standard population. ${ }^{12}$ 
SK TOTAL
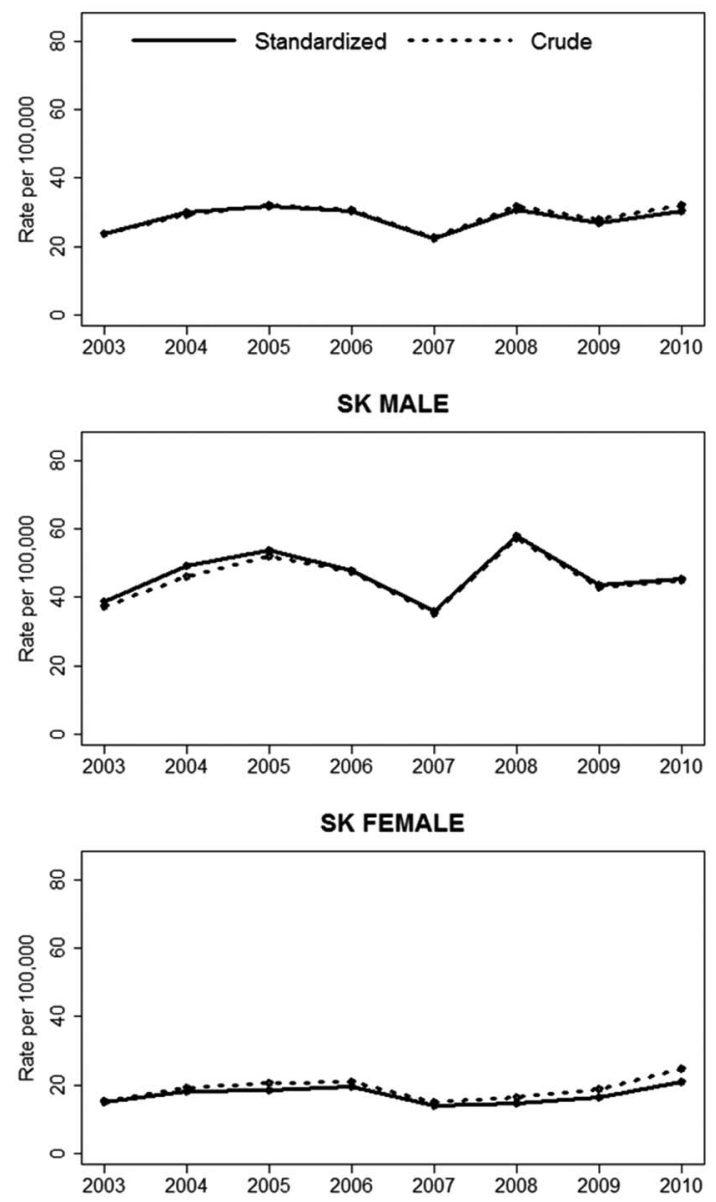

AT TOTAL

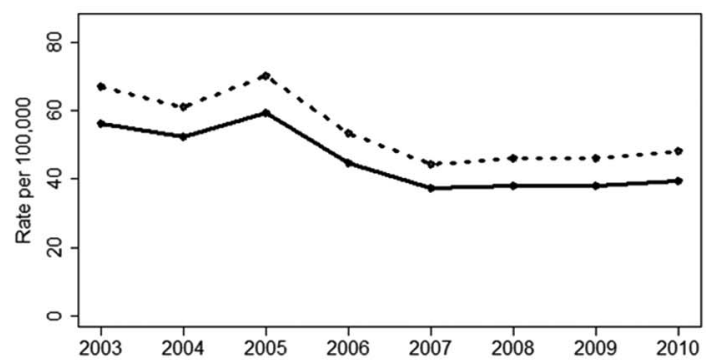

AT MALE

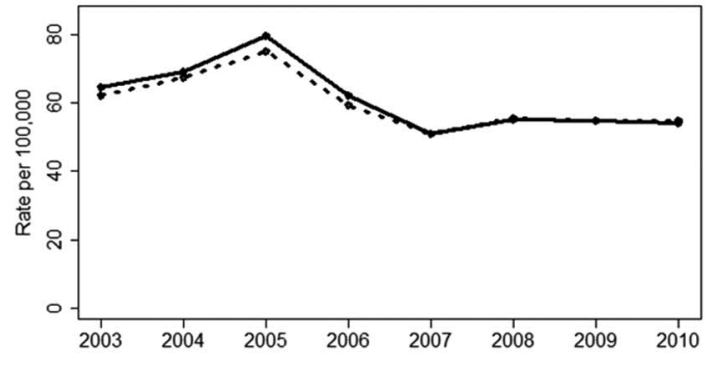

AT FEMALE

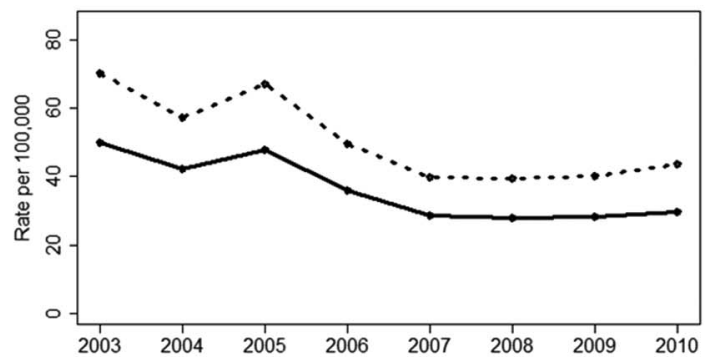

Figure 1 Crude and standardised fall-related mortality rates per 100000 person-years in Slovakia and Austria in 2003-2010. SK, Slovakia; AT, Austria.

Austria (rate ratio=0.84). In all other age groups the rates in Austria were higher, compared to Slovakia (1.8 times higher in 75-84 years old, 2.5 times higher in $85-$ 94 years old and 2.9 times higher in the population over 95 years). Again, the rate ratios were higher in females, compared to males. The crude overall mortality rates were higher in Austria by a factor of 1.9. The trends of between country rate ratios over the studied period are graphically summarised in figure 2 .
The underlying cause of death was most often a head injury or a hip injury (they accounted for over $75 \%$ of all injuries). Their distribution by country and sex is presented in figure 3. A clearly larger proportion of hip fractures is present in females in both countries. In males, the proportion of head injuries was higher in Slovakia.

In the ESM we present a detailed analysis of the dynamics of the proportions of the elderly population in relation to the total population in both countries

Table 2 Annual average rate ratios of fall-related mortality per 100000 person-years by age groups in Slovakia 2003$2012^{*} \dagger$

\begin{tabular}{|c|c|c|c|c|c|c|c|c|}
\hline \multirow[b]{2}{*}{ Country } & \multirow[b]{2}{*}{ Subgroup } & \multirow[b]{2}{*}{$65-74$} & \multicolumn{2}{|l|}{$75-84$} & \multicolumn{2}{|l|}{ 85-94 } & \multicolumn{2}{|l|}{$95+$} \\
\hline & & & Ratio & $95 \% \mathrm{Cl}$ & Ratio & $95 \% \mathrm{Cl}$ & Ratio & $95 \% \mathrm{Cl}$ \\
\hline \multirow[t]{3}{*}{ Slovakia } & Male & 1 & 1.4 & 0.9 to 2.1 & 2.8 & 1.4 to 4.9 & 6.4 & 0.98 to 20.5 \\
\hline & Female & 1 & 2.8 & 1.5 to 5.2 & 8.9 & 4.7 to 17.1 & 17.5 & 3.9 to 52.6 \\
\hline & Total & 1 & 1.7 & 1.2 to 2.4 & 4.1 & 2.7 to 5.9 & 8.2 & 2.8 to 18.4 \\
\hline \multirow[t]{3}{*}{ Austria } & Male & 1 & 3.1 & 2.4 to 4.1 & 9.9 & 7.4 to 13.3 & 25.7 & 13.3 to 45.2 \\
\hline & Female & 1 & 5.6 & 3.9 to 8.1 & 19.7 & 13.9 to 28.5 & 47 & 29.3 to 75.3 \\
\hline & Total & 1 & 3.7 & 3 to 4.6 & 12 & 9.7 to 14.9 & 28.4 & 20 to 39.6 \\
\hline
\end{tabular}

*The rates in age group 65-74 are used as reference, all other rate ratios are relative to this category.

†Please see electronic supplementary material for detailed data calculated for each year under study. 
Table 3 Rate ratios of fall-related mortality per 100000 person-years by sex groups in Slovakia and Austria 2003$2012^{*}$

\begin{tabular}{llll}
\hline & \multicolumn{3}{l}{ Males } \\
\cline { 3 - 4 } Year & Females & Ratio & $95 \%$ Cl \\
\hline Austria & & & \\
2003 & 1 & 0.87 & 0.77 to 1.02 \\
2004 & 1 & 1.17 & 1.02 to 1.35 \\
2005 & 1 & 1.12 & 0.98 to 1.28 \\
2006 & 1 & 1.2 & 1.04 to 1.39 \\
2007 & 1 & 1.28 & 1.09 to 1.49 \\
2008 & 1 & 1.4 & 1.2 to 1.63 \\
2009 & 1 & 1.37 & 1.18 to 1.59 \\
2010 & 1 & 1.26 & 1.09 to 1.46 \\
Annual average & 1 & 1.18 & 1.02 to 1.36 \\
Slovakia & & & \\
2003 & 1 & 2.41 & 1.74 to 3.38 \\
2004 & 1 & 2.4 & 1.79 to 3.24 \\
2005 & 1 & 2.54 & 1.92 to 3.38 \\
2006 & 1 & 2.26 & 1.7 to 3 \\
2007 & 1 & 2.34 & 1.68 to 3.27 \\
2008 & 1 & 3.51 & 2.63 to 4.72 \\
2009 & 1 & 2.25 & 1.68 to 3.02 \\
2010 & 1 & 1.82 & 1.39 to 2.38 \\
Annual average & 1 & 2.4 & 1.8 to 3.23 \\
\hline *The presented rate ratios are calculated using females as a \\
reference category. & & & \\
& & &
\end{tabular}

(see online supplementary table S5 and supplementary figure S1). In both countries the proportions of persons 65 years and older and 80 years and older out of the total population are analysed. Our findings show an increasing pattern in both categories and both countries. However, the size of proportions and their increase were higher in Austria: the proportion of the population of 65 year and older grew from $15.4 \%$ in 2003 to $17.7 \%$ in 2010 and the proportion of population of 80 years and older grew from 4 to $4.8 \%$ ). These patterns were more apparent in the female population: in 65 years and older increase from $18.4 \%$ to $20.1 \%$ compared to increase from $12.3 \%$ to $15.1 \%$ in males and in 80 years and older increase from $5.6 \%$ to $6.4 \%$ compared to $2.3 \%$ to $3.2 \%$ in males. The overall increase observed in Slovakia in the $65+$ group was from $11.5 \%$ to $12.4 \%$ and in the 80 + group from $2.3 \%$ to $2.8 \%$. Again, this pattern was more apparent in females where it increased from $14 \%$ to $15.1 \%$ in 65 years and older and from $3 \%$ to $3.8 \%$ in 80 years and older (increase in males was from $8.9 \%$ to $9.5 \%$ in 65 years and older and from $1.5 \%$ to $1.7 \%$ in 80 years and older). Thus, both the size of the proportions and the size of the increase is higher in Austria which translates into larger population at risk for elderly falls, compared to Slovakia.

\section{DISCUSSION}

We conducted a population-based epidemiological study with the aim to identify the differences in patterns of unintentional fall-related mortality rates in the elderly population of two countries with different demographic structure. Our main findings are:

1. Mortality rates in Austria and Slovakia increased with increasing age; the size of the increase being larger in older age groups and considerably more apparent in females.

2. Overall mortality rates in males were higher than in females in both countries; the differences being higher in Slovakia.

3. Crude and standardised overall mortality rates over the analysed period were decreasing in Austria (both sexes) and increasing in Slovakia (especially in males).

4. Crude age specific mortality rates were smaller in Austria in the age group of $65-74$ and higher in older age groups, compared to Slovakia.

5. Injuries to the head and hip were most commonly the underlying cause of death; hip fractures were more common in females and head injuries in males.

6. The age standardised annual average fall-related mortality rates for the period under study in the Austrian elderly population was 45.03 and in Slovakia 28.22.

Unintentional falls are prominent among external causes of injury, they are a major cause of morbidity and a leading cause of death in the elderly population. ${ }^{1}{ }^{18}$ The fall-related death rates in the general populations of European countries vary significantly and range from 25 to 132; the rate for Slovakia for the period of 2008-2010 was 52 and the rate for Austria 39. ${ }^{2}$ Standardised fallrelated mortality rates in the elderly populations of European countries ranged from 58 to $280 .^{2}$ Studies focusing on the elderly population in other (non-European) countries reported mortality rates of 52.4 (for 2010) in the USA, ${ }^{18}$ and 60.8 (for 2009) in Canada. ${ }^{19}$ In our study the overall age standardised mortality rates in the elderly were 28.22 for Slovakia and 45.03 for Austria. A distinction is therefore apparent between mortality rates in the general and the elderly populations in Slovakia and Austria: the fall-related mortality rate in the general population was higher in Slovakia whereas the mortality rate in elderly population was higher in Austria. These finding suggest that the between-country differences in fall-related mortality rates are considerably larger and reversed in the elderly population compared to the general population.

This phenomenon could be partly attributed to the ageing of the population, which has been identified as one of the key drivers of the increasing fall-related mortality worldwide. ${ }^{13691018}$ In general, the increasing size of the elderly population results in an increase in the population under the highest risk of fall-related death. This translates into an exponential increase of mortality rates in higher age groups, especially in octogenarians and older. ${ }^{1}$ Our finding confirm this: the between age-group rate ratios were substantially higher for the ages of 85 years and older and were much more apparent in Austria than were in Slovakia (tables 3 and 4). 
Table 4 Rate ratios of fall-related mortality per 100000 person-years by country in Austria, compared to Slovakia 2003$2012^{*}$

\begin{tabular}{|c|c|c|c|c|c|c|c|c|c|c|}
\hline \multirow[b]{2}{*}{ Year/age group } & \multicolumn{2}{|c|}{$65-74$} & \multicolumn{2}{|c|}{$75-84$} & \multicolumn{2}{|l|}{$85-94$} & \multicolumn{2}{|l|}{$95+$} & \multicolumn{2}{|c|}{ Total Crude } \\
\hline & Ratio & $95 \% \mathrm{Cl}$ & Ratio & $95 \% \mathrm{Cl}$ & Ratio & $95 \% \mathrm{Cl}$ & Ratio & $95 \% \mathrm{Cl}$ & Ratio & $95 \% \mathrm{Cl}$ \\
\hline \multicolumn{11}{|l|}{ Male } \\
\hline 2003 & 0.99 & 0.7 to 1.5 & 1.5 & 1.1 to 2.2 & 4.3 & 2.1 to 10.2 & 1.7 & 0.4 to 12.6 & 1.4 & 1.3 to 2.1 \\
\hline 2004 & 0.7 & 0.5 to 1.04 & 2.2 & 1.5 to 3.3 & 1.9 & 1.2 to 3.4 & 3.5 & 0.6 to 86.6 & 1.5 & 1.2 to 1.8 \\
\hline 2005 & 0.8 & 0.5 to 1.1 & 1.5 & 1.1 to 2.1 & 3.1 & 1.8 to 5.6 & 4.1 & 1.2 to 28.1 & 1.5 & 1.2 to 1.7 \\
\hline 2006 & 0.5 & 0.3 to 0.8 & 1.4 & 0.99 to 1.9 & 4.4 & 2.3 to 9.8 & 3.9 & 1.1 to 26.8 & 1.3 & 1.02 to 1.6 \\
\hline 2007 & 0.8 & 0.5 to 1.1 & 2.1 & 1.4 to 3.2 & 1.9 & 1.1 to 3.7 & 3.9 & 0.7 to 98.3 & 1.4 & 1.1 to 1.8 \\
\hline 2008 & 0.5 & 0.3 to 0.6 & 1.2 & 0.8 to 1.6 & 1.8 & 1.1 to 3.2 & 2.3 & 0.6 to 16.5 & 0.96 & 0.8 to 1.1 \\
\hline 2009 & 0.6 & 0.4 to 0.9 & 1.8 & 1.2 to 2.6 & 2 & 1.2 to 3.7 & 5.8 & 1.2 to 142.4 & 1.3 & 1.04 to 1.6 \\
\hline 2010 & 0.9 & 0.6 to 1.2 & 1.2 & 0.8 to 1.6 & 2.1 & 1.2 to 3.8 & 1.4 & 0.5 to 5.1 & 1.2 & 0.99 to 1.5 \\
\hline Annual average & 0.7 & 0.4 to 0.97 & 1.5 & 1.1 to 2.2 & 2.5 & 1.4 to 4.6 & 2.8 & 0.7 to 19.3 & 1.3 & 1.1 to 1.6 \\
\hline \multicolumn{11}{|l|}{ Female } \\
\hline 2003 & 1.4 & 0.7 to 2.5 & 2.8 & 1.9 to 4.2 & 5.7 & 3.3 to 10.8 & 12.2 & 2.7 to 283.5 & 4.5 & 3.5 to 5.9 \\
\hline 2004 & 2 & 1.03 to 4.1 & 2.3 & 1.6 to 3.3 & 2.4 & 1.6 to 3.8 & 2.3 & 0.9 to 8 & 3 & 2.4 to 3.8 \\
\hline 2005 & 1.5 & 0.8 to 2.8 & 2.1 & 1.5 to 2.8 & 4.4 & 2.7 to 7.6 & 4.2 & 1.5 to 17.8 & 3.3 & 2.6 to 4.1 \\
\hline 2006 & 0.95 & 0.5 to 1.6 & 2 & 1.4 to 2.9 & 2.3 & 1.5 to 3.6 & 8.3 & 1.8 to 193.8 & 2.4 & 1.9 to 3 \\
\hline 2007 & 0.9 & 0.5 to 1.5 & 2.3 & 1.5 to 3.6 & 3.9 & 2.2 to 7.3 & 2.3 & 0.8 to 9.9 & 2.6 & 2 to 3.5 \\
\hline 2008 & 1.1 & 0.6 to 2 & 1.9 & 1.3 to 2.9 & 2.7 & 1.7 to 4.6 & 3.1 & 0.9 to 21 & 2.4 & 1.9 to 3.1 \\
\hline 2009 & 1.3 & 0.6 to 2.4 & 1.6 & 1.2 to 2.8 & 1.9 & 1.2 to 2.8 & 1.6 & 0.6 to 5.5 & 2.1 & 1.7 to 2.7 \\
\hline 2010 & 0.99 & 0.5 to 1.8 & 1.6 & 1.1 to 2.3 & 1.3 & 0.95 to 1.9 & 2.5 & 1.01 to 8.6 & 1.8 & 1.4 to 2.2 \\
\hline Annual average & 1.2 & 0.6 to 2.1 & 2.3 & 1.6 to 3.4 & 2.6 & 1.7 to 4.2 & 3.1 & 1.1 to 13.6 & 2.7 & 2.1 to 3.4 \\
\hline \multicolumn{11}{|l|}{ Total } \\
\hline 2003 & 1.2 & 0.8 to 1.5 & 2.1 & 1.6 to 2.7 & 5.2 & 3.6 to 8.6 & 5.8 & 2.1 to 24.3 & 2.8 & 2.4 to 3.3 \\
\hline 2004 & 1.01 & 0.7 to 1.3 & 2.3 & 1.7 to 2.9 & 2.2 & 1.5 to 3.1 & 2.6 & 1.1 to 7.7 & 2.1 & 1.8 to 2.4 \\
\hline 2005 & 0.96 & 0.7 to 1.2 & 1.8 & 1.4 to 2.2 & 3.7 & 2.6 to 5.6 & 4 & 1.8 to 11.7 & 2.2 & 1.9 to 2.5 \\
\hline 2006 & 0.7 & 0.5 to 0.9 & 1.7 & 1.3 to 2.1 & 2.8 & 1.9 to 4.1 & 5.2 & 1.9 to 22 & 1.7 & 1.5 to 2 \\
\hline 2007 & 0.8 & 0.6 to 1.1 & 2.3 & 1.7 to 3.1 & 2.9 & 1.9 to 4.5 & 2.7 & 1.05 to 9.11 & 2 & 1.6 to 2.4 \\
\hline 2008 & 0.6 & 0.4 to 0.8 & 1.5 & 1.1 to 1.9 & 2.3 & 1.6 to 3.3 & 2.6 & 1.04 to 9 & 1.5 & 1.3 to 1.7 \\
\hline 2009 & 0.9 & 0.5 to 1.1 & 1.9 & 1.4 to 2.4 & 1.9 & 1.3 to 2.7 & 2.9 & 1.1 to 9.8 & 1.7 & 1.4 to 2 \\
\hline 2010 & 0.95 & 0.7 to 1.2 & 1.4 & 1.1 to 1.8 & 1.5 & 1.1 to 2 & 1.9 & 0.95 to 4.4 & 1.5 & 1.3 to 1.7 \\
\hline Annual average & 0.8 & 0.6 to 1.1 & 1.8 & 1.4 to 2.4 & 2.5 & 1.8 to 3.7 & 2.9 & 1.3 to 8.6 & 1.9 & 1.6 to 2.2 \\
\hline
\end{tabular}

Considering the higher life expectancy in Austria, ${ }^{13} 14$ higher proportions of persons above 65 years and above 80 years in the population of Austria, and their more apparent increase over the studied period (see online supplementary table S5 and supplementary figure S1) we could assume that the observed between-country difference in the magnitude of the problem could have been partly driven by the 'older' population of Austria compared to Slovakia. However, we note that this assumptions contradicts the fact that the differences in mortality rates remained notable even after age standardisation. Thus, other factors that are beyond the scope of this
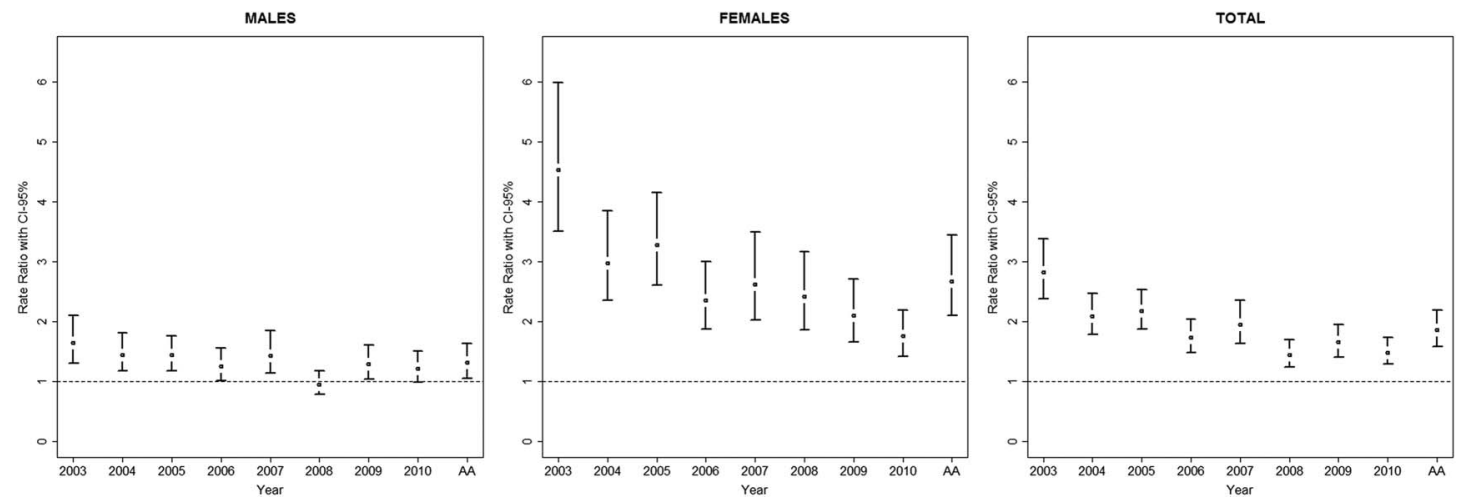

Figure 2 Between-country mortality rate ratios 2003-2010 and 95\% Cls by sex. AA, annual average; ratios are calculated using Slovakia as a reference (the value of 1 was assigned to each rate in Slovakia and all rates on the figure are relative to these). 

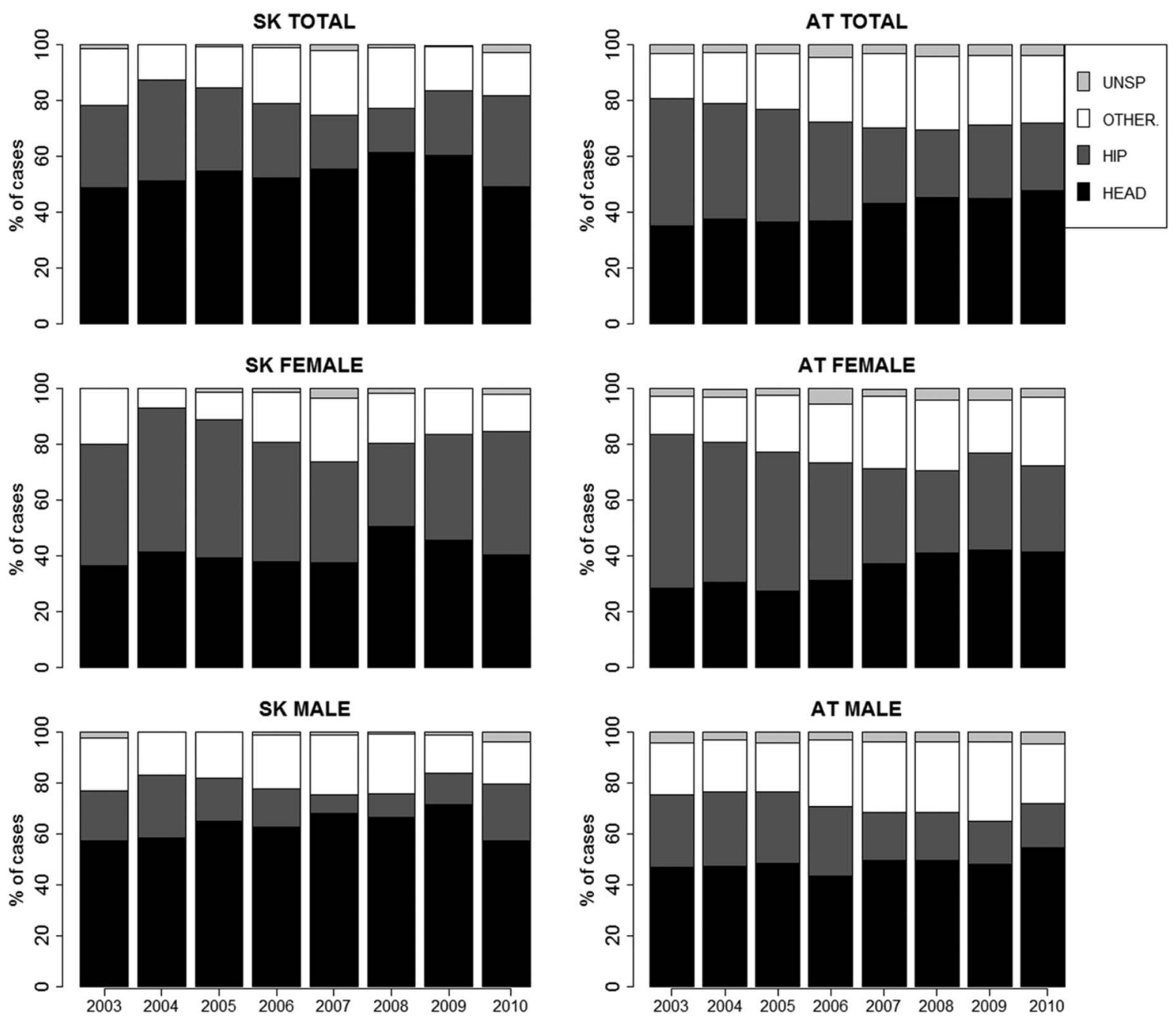

Figure 3 Anatomic distribution of the most significant injury (listed as underlying cause of death) in fall-related fatalities in Slovakia and Austria in 2003-2010. SK, Slovakia, AT, Austria.

paper are likely to influence the differences in mortality rates.

One such factor might be the overall number of fallrelated injuries. Although our study primarily focused on fatalities, it is important to note that this is only one part of the problem. Besides high rates of mortalities, there are high rates of hospitalisations and outpatient visits after fall-related injuries. In Europe the ratio of fatal:hospitalised:outpatient cases in 2008-2010 was 223 000:5 700 000:33 $900000 .^{2}$ On one hand, larger population at risk (65 years and older) may mean increasing overall number of fall-related injuries. On the other hand, if the occurrence of these injuries would be continually shifting towards higher age groups (eg, 80 years and older, caused by the rapid increase of population in these age groups) the relationship between the overall incidence and mortality might become exponential rather than linear. Ultimately, this may cause the mortality increasing at higher rates than the overall incidence of falls. However, based on the data that was available for our analysis we were not able to elaborate on this hypothesis (the overall number of outpatient and hospitalised cases was not available). We suggest that further research is carried out in order to elucidate these complex relationships.

The ratio of fatal: hospitalised: outpatient cases also illustrates that the magnitude of this public health problem goes far beyond the fatalities. The cost of injury-related healthcare in Europe (EU-27) is estimated at $€ 78$ billion (of which a large portion is attributable to fall-related injuries in the elderly) and about a million people in Europe are permanently disabled as a consequence of injuries annually. ${ }^{2}$ Findings from the UK suggest that the majority of the cost in case of fall-related injuries in the elderly can be attributed to inpatient admissions (about 50\%). ${ }^{20}$

Although the life expectancy at birth in Slovakia lags behind the Austrian, it is increasing more rapidly, compared to Austria: from 73.9 in 2005 to 76.1 in $2012^{14}$ (the life expectancy in Austria stayed 81 years for this period $\left.^{13}\right)$. If such pace of increase is maintained a rapid increase of the size of the elderly population can be expected in Slovakia in the coming years which will be coupled with higher incidence of fall-related injuries 
and possible increase in related mortality rates. This will inevitably bring challenges for the healthcare system, social care system, for the families and the population as a whole.

Other factors, such as quality of healthcare and social services might influence the dynamics of the mortality rates in each specific country. A previous study showed that higher level of economy of the country translated into higher quality of healthcare, which in turn improved the outcome of patients (mortality and degree of disability) after traumatic brain injuries (Austria and Slovakia were both part of the study) ${ }^{21}$ As in our study head injuries were identified as one the most common injuries leading to death, we could assume that the decreasing trend of fatalities (despite the stagnating/ increasing life expectancy) in Austria could be partially explained by higher quality of healthcare in Austria compared to Slovakia.

\section{Study limitations}

We admit that there are potential limitations to our study. For all analyses in this study, administrative data have been used and the authors had no control over the process of diagnostic coding or any other processes related to the preparation of the data sets. Eventual inaccuracies in coding of the external cause of death or the underlying cause of death that were present in the obtained data sets could bias some of our results. However, we have confidence in the procedures set up in both countries and therefore do not expect any major influence on our principal findings. In addition, further external factors that could not be analysed in this study might be considered that could confound the observed differences such as possible variations in urban-rural living or different weather conditions.

\section{CONCLUSION}

We conclude that higher proportions of the elderly population of Austria could have contributed to the higher fall-related mortality rates compared to Slovakia, especially in females over 80 years. Our study quantified the differences between two countries with different structure of the elderly population and these findings could be used in planning future needs of health and social services and to plan prevention in countries where a rapid increase in age of the population can be foreseen.

Acknowledgements The authors would like to thank Dr Alexandra Brazinova, $\mathrm{PhD}$ and Veronika Buckova, PhD for their help in obtaining the data from the Slovakian authorities. The authors thank the representatives of the Statistical Offices in Austria and Slovakia for their help in providing the necessary data. Marek Majdan would like to dedicate this paper to the memory of professor Walter Mauritz who passed away in May 2015. He was an excellent researcher and a great friend.

Contributors MM designed the study, wrote the draft manuscript, rewrote the manuscript after comments, conducted all statistical analyses and prepared the revised version of the manuscript. WM designed the study, wrote parts of the discussion and results and critically reviewed the draft manuscript.

Competing interests None declared.
Provenance and peer review Not commissioned; externally peer reviewed.

Data sharing statement No additional data are available.

Open Access This is an Open Access article distributed in accordance with the Creative Commons Attribution Non Commercial (CC BY-NC 4.0) license, which permits others to distribute, remix, adapt, build upon this work noncommercially, and license their derivative works on different terms, provided the original work is properly cited and the use is non-commercial. See: http:// creativecommons.org/licenses/by-nc/4.0/

\section{REFERENCES}

1. WHO. WHO global report on falls prevention in older age. Geneva: World Health Organization, 2007.

2. EuroSafe. Injuries in the European Union: summary of injury statistics for the years 2008-2010. Amsterdam: European Association for Injury Prevention and Safety Promotion (EuroSafe), 2013.

3. Tinetti ME. Clinical practice. Preventing falls in elderly persons. N Engl J Med 2003;348:42-9.

4. Todd C, Skelton D. What are the main risk factors for falls amongst older people and what are the most effective interventions to prevent these falls? (Health evidence network report). Copenhagen: WHO Regional Office for Europe, 2004.

5. Hestekin H, O'Driscoll T, Williams JS, et al. Measuring prevalence and risk factors for fall-related injury in older adults in low- and middle-income countries: results from the WHO Study on Global AGEing and Adult Health. Geneva: WHO, 2013.

6. O'Loughlin JL, Robitaille $\mathrm{Y}$, Boivin JF, et al. Incidence of and risk factors for falls and injurious falls among the community-dwelling elderly. Am J Epidemiol 1993;137:342-54.

7. Rubenstein LZ. Falls in older people: epidemiology, risk factors and strategies for prevention. Age Ageing 2006;35(Suppl 2):ii37-41.

8. Inui TS, Parina R, Chang DC, et al. Mortality after ground-level fall in the elderly patient taking oral anticoagulation for atrial fibrillation/ flutter: a long-term analysis of risk versus benefit. $J$ Trauma Acute Care Surg 2014;76:642-9; discussion 49-50.

9. Huisman M, Kunst AE, Mackenbach JP. Socioeconomic inequalities in morbidity among the elderly; a European overview. Soc Sci Med 2003;57:861-73.

10. Petridou ET, Dikalioti SK, Dessypris N, et al. The evolution of unintentional injury mortality among elderly in Europe. J Aging Health 2008;20:159-82.

11. WHO. The ICD-10 classification of mental and behavioural disorders: clinical descriptions and diagnostic guidelines. Geneva: World Health Organization, 1992.

12. Ahmad OB, Boschi-Pinto C, Lopez AD, et al. Age standardization of rates: a new WHO standard (GPE Discussion Paper Series: no.31). Geneva: World Health Organization, 2001.

13. The-World-Bank. World Development Indicators: Austria. Secondary World Development Indicators: Austria. 2015. http://data.worldbank. org/country/austria

14. The World Bank. World Development Indicators: Slovakia Secondary World Development Indicators: Slovakia. 2015. http:// data.worldbank.org/country/slovak-republic

15. The_World_Bank. World Bank, International Comparison Program database. Secondary World Bank, International Comparison Program database. 2015. http://data.worldbank.org/indicator/NY. GNP.PCAP.PP.CD

16. EuroStat. GDP per capita in PPS. Secondary GDP per capita in PPS. 2015. http://ec.europa.eu/eurostat/tgm/table.do? tab=table\&init $=1$ \&language $=e n \& p c o d e=t e c 00114$ \& plugin $=1$

17. R-Core-Team. R: A language and environment for statistical computing. Secondary R: A language and environment for statistical computing. 2013. http://www.R-project.org/

18. Stevens JA, Rudd RA. Circumstances and contributing causes of fall deaths among persons aged 65 and older: United States, 2010. $J$ Am Geriatr Soc 2014;62:470-5.

19. Gagné M, Robitaille $\mathrm{Y}$, Jean $\mathrm{S}$, et al. Changes in fall-related mortality in older adults in Quebec, 1981-2009. Chronic Dis Inj Can 2013;33:226-35.

20. Scuffham $P$, Chaplin S, Legood R. Incidence and costs of unintentional falls in older people in the United Kingdom. $J$ Epidemiol Community Health 2003;57:740-4.

21. Mauritz W, Wilbacher I, Majdan M, et al. Epidemiology, treatment and outcome of patients after severe traumatic brain injury in European regions with different economic status. Eur J Public Health 2008;18:575-80. 